\title{
El pensamiento de Antonio Benítez Rojo: "Un estremecido colibrí bebiendo de una flor"1
}

\author{
The Thought of Antonio Benítez Rojo, "A Shaken \\ Hummingbird Drinking from a Flower" \\ O pensamento de Antonio Benítez Rojo: “Um beija- \\ flor abalado bebendo de uma flor"
}

\section{Liliana Ramírez}

PONTIFICIA UNIVERSIDAD JAVERIANA, BOGOTÁ, COLOMBIA

Profesora titular del Departamento de Literatura de la Pontificia

Universidad Javeriana, Bogotá. PhD en Literatura, University of

Massachusetts, Amherst. Es autora de varios artículos en revistas

especializadas, del libro Entre fronteras: latinoamericanos y literaturas

(Editorial Pontificia Universidad Javeriana, 2007), y coeditora del

libro de ensayos de Montserrat Ordóñez De voces y amores (Norma,

2004). Correo electrónico: liliana-ramirez@javeriana.edu.co

Artículo de reflexión

Documento accesible en línea desde la siguiente dirección: http://revistas.javeriana.edu.co

doi:10.11144/Javeriana.CL18-36.pabr

1 Esta es una imagen que Benítez Rojo usa constantemente en La isla que se repite. 


\section{Resumen}

Este artículo pretende dar cuenta de algunos aportes del pensamiento del novelista y teórico cubano Antonio Benítez Rojo, inscribiéndolo en el debate que desde hace varias décadas han dado pensadores como Fernández Retamar, Cornejo Polar y Mignolo, con respecto a la necesidad de categorías propias que den cuenta del carácter específico de nuestras manifestaciones culturales. Partiendo de lo mirado mismo, en este caso el Caribe, Benítez Rojo propone pensar el lenguaje como ritmo-palabra, pensar el tiempo como perfomance, los juegos de la transculturación caribeña como criollización y mirar desde el contrapunto y no desde causas y efectos, para poder entrar en relación con el pluralismo de las voces y los ritmos en movimiento de esa isla que se repite siempre en la diferencia.

Palabras clave: Benítez Rojo; criollización; estudios caribeños; teoría latinoamericana y caribeña

\section{Abstract}

The purpose of this article is to account for some of the contributions provided by the thoughts of the cuban novelist and theorist Antonio Benítez Rojo, inscribing him in the debate that has for some decades been developed by thinkers such as Fernández Retamar, Cornejo Polar, and Mignolo, a debate centered upon the need to create categories that account for the specific character of our cultural manifestations. Starting from the things observed -in this case the Caribbean region-Benítez Rojo proposes to think language as "word-rhythm", think time as performance, caribbean transculturation as creolization, and to develop a "counterpoint" structure of thought, instead of a cause-effect structure; in order to enter the relationship of the pluralism of voices and rhythms in movement of this repeating yet constantly changing - island.

Keywords: Benítez Rojo;

Caribbean Studies; creolization;

latin-american and caribbean

theory

\section{Resumo}

Este artigo pretende explicar algumas contribuições do pensamento do romancista e teórico cubano Antonio Benítez Rojo, inscrevendo ele no debate que faz várias décadas deram pensadores como Fernández Retamar, Cornejo Polar e Mignolo, no que diz respeito à necessidade de categorias próprias para dar conta do carácter específico das nossas manifestações culturais. Partindo do próprio observado, neste caso o Caribe, Benítez Rojo propõe pensar a linguagem como ritmo-palavra, pensar o tempo como performance, os jogos da transculturação caribenha como crioulização e olhar desde o contraponto e não desde causas e efeitos, para poder entrar no relacionamento com o pluralismo das vozes e ritmos em movimento dessa ilha que se repete sempre na diferença.

Palavras-chave: pós-hegemonia; ultraesquerdismo; latinoamericanismo; estudos culturais.

RECIBIDO: 17 DE NOVIEMBRE DE 2013. APROBADO: 11 DE DICIEMBRE DE 2013. DISPONIBLE EN LÍNEA: 30 DE JULIO DE 2014.

\section{Cómo citar este artículo:}

Ramírez, Liliana. "El pensamiento de Antonio Benítez Rojo: 'Un estremecido colibrí bebiendo de una flor"'. Cuadernos de Literatura 18.36 (2014): 296-309. http://dx.doi.org/10.11144/Javeriana.CL18-36.pabr 
RECUERDo a Benítez Rojo caminando por entre la nieve para llegar a su oficina de Amherst College, Massachusetts. Lo veo como un ser dislocado, un fragmento caribe en medio del blanco y el frío. Entra al salón de clase, mira de frente, se oye su voz y esa dislocación se hace carnaval. Habla del Caribe, de Lezama, Carpentier, Fernando Ortiz, Tres tristes tigres, La guaracha del macho Camacho. Nos habla de la criollización, la plantación, el contrapunteo, la historia, el vudú, la santería. En algún momento de la clase, con mucha seriedad, nos dice que la ventaja de la Historia es que en ella los elefantes no vuelan y por eso no estamos sepultados en su caca. Y cuando ya nosotros estamos convencidos de la ventaja de la Historia, nos dice: la ventaja de la novela es que si en ella los elefantes vuelan, no necesariamente defecan. Para hacer presente lo uncanny, nos cuenta que ha soñado que una noche él está en una acalorada reunión y sale a tomar un poco de aire. Camina hasta un arrollo y junto a la orilla se encuentra cuatro personas junto a un cadáver asado, ya dispuestas a merendárselo; pero al ver a quien los veía, huyen. Antonio ve entonces cómo el cadáver se arrastra hacia el río y nada; en un momento saca la cara para tomar aire. Es él mismo: Antonio Benítez Rojo.

Hoy, diez años después de esas clases, su palabra-performance vuelve a hacerse vida mientras escribo estas páginas. En la escritura como ritual que acontece, se hace presente de nuevo su ritmo en mis notas de clase, en sus artículos y libros; lo caribeño presente como ese big bang que nunca termina de suceder y se sigue desbordando. Me he encontrado con los ritmos de Benítez Rojo en diferentes momentos, desde diferentes orillas: antes, la del ser una estudiante extranjera en Amherst, ese pueblo diminuto al norte de Estados Unidos hasta el que llegaban los ecos de la plantación cuando Benítez Rojo hablaba y todos vivíamos en esa especie de simulacro en el que vivimos los que hemos sido extranjeros; ahora, desde mi ser lectora latinoamericana en búsqueda de miradas orilleras que logren dar cuenta de lo que Retamar y Cornejo Polar llaman el carácter específico de nuestras literaturas.

\section{El debate por categorías propias}

Este debate tiene ya décadas, sin superarse ni resolverse del todo. Uno de sus momentos cruciales fue la publicación del artículo (y luego libro) de Fernández Retamar "Para una teoría de la literatura hispanoamericana" en 1975, en el cual reclamaba una teoría latinoamericana que a partir de categorías propias y no eurocentristas diera cuenta de los procesos específicos de la literatura latinoamericana, asumida como expresión y afirmación de nuestra especificidad. Retamar cuestionaba los trabajos teóricos que al partir de modelos totalizantes, como el estructuralismo, pretendían llegar a conclusiones "generales", que según él en 
realidad solo encubrían una condición colonial. Reclamaba una visión descolonizada desde la crítica y la teoría propias que diera cuenta, por ejemplo, de que la línea central de nuestra literatura no es la purista, el arte por el arte propuesto por Alfonso Reyes, sino "la amulatada, la híbrida, la ancilar", como se ve, según él, en el predominio de géneros "instrumentales" como las crónicas, los discursos, las cartas, los diarios, las memorias y en el uso antropófago que los textos latinoamericanos hacen de las corrientes literarias europeas y sus rasgos (Retamar 109). Retamar muestra la necesidad de categorías propias para hacer historia de la literatura latinoamericana. Critica las periodizaciones tradicionales que se postulan como universales pero no lo son. Se pregunta: ¿qué sentido tiene organizar nuestra literatura a partir de movimientos y periodos de la historia europea? Según él, hay que hablar de "periodos inequívocamente nuestros [...] serán momentos nuestros de estar en el mundo. Nuestros orígenes coloniales, nuestro subsiguiente proceso neocolonial, y la trabajosa configuración de un rostro propio a través de nuestra historia" (122). Y sobre todo, cuestiona la crítica literaria que dice hacer crítica pura y se pretende objetiva (estética y estilística), desconociendo otras nociones de literatura que rigen en realidad la literatura latinoamericana.

Veinte años después, Cornejo Polar, en su artículo "Para una teoría literaria hispanoamericana: a veinte años de un debate decisivo", retoma la importancia de la propuesta y la pertinencia de hablar desde categorías propias, pero critica el proyecto de Retamar al señalar la imposibilidad de pensar nuestras literaturas y nuestra identidad en términos de unidad "coherente y homogénea", pues estas se producen y transforman dentro de una compleja red de discursos inscritos en una historia asimétrica de ritmos y temporalidades ("Para una teoría" 249). Cornejo reivindica enfáticamente "la condición múltiple, plural, híbrida, heterogénea o transcultural de los distintos discursos y de los varios sistemas literarios que se producen en nuestra América" (248); señala no solo lo andino en contraste, por ejemplo, con lo caribeño dentro de América Latina, sino lo plural de lo andino mismo en el que conviven textos escritos en español y bajo códigos estéticos derivados de la literatura europea y textos orales en quechua o aimara. De esta manera, Cornejo pone en tela de juicio la pretensión unificadora que hay detrás del "nuestra América" de Retamar.

Por la misma época Walter Mignolo, en el artículo "Teorizar a través de fronteras culturales" (1991), participa en el debate. Destaca el que Retamar señale que la llamada "teoría de la literatura es la teoría de UNA literatura" porque para él, tampoco es posible hablar ni de Una literatura universal ni de Una teoría en singular que dé cuenta de ella (105). Sin embargo, critica a Retamar porque al reclamar una teoría sobre "nuestra América", asume "nuestra América" como 
una esencia y no como una construcción y así, le asigna a la teoría la función de "revelar la esencia de la literatura regional" y no asume "la actividad teórica como una práctica que desde los márgenes pueda, críticamente, enfrentarse a la actividad teórica como una práctica del centro" (105-106).

Ahora bien, ¿cómo conversa el pensamiento de Benítez Rojo con este debate? Parecería estar de acuerdo con el proyecto de Retamar de pensar lo específico desde categorías y estructuras de pensamiento "propias", aunque eso de "propias" para seres dislocados de su propio nombre como los caribeños ya es un problema. Este énfasis en lo local lo separa del análisis estructuralista de los años 60 que definió lo caribeño en términos de oposiciones binarias como cultura dominante/cultura dominada, cultura del colonizador/cultura del colonizado, cultura imperialista/cultura socialista, etc. (Benítez Rojo 391). Reconoce que esos esfuerzos fueron importantes porque impulsaron un discurso caribeño, pero señala que homogeneizaron a Europa y África como polos y además restaron importancia a Indoamérica y Asia en ese proceso. Por otra parte, dichos discursos "cristalizaron" en una síntesis estable los componentes culturales concebidos en un proceso de mestizaje progresista, que como señala Cornejo pasó también para el caso latinoamericano.

Así mismo, Benítez Rojo anota la influencia que tuvo la posmodernidad en los años 80 en el discurso caribeño y, aunque reconoce su importancia porque "ayudó a desmantelar los viejos absolutos", señala también sus limitaciones porque esta se centra en la crítica a las disciplinas humanísticas de Occidente y no tiene en cuenta lo específico de la problemática política, económica y sociocultural del Caribe (391). Además, según él, el pensamiento posmoderno al proponerse como científico "despoja de autoridad al 'conocimiento narrativo", del cual depende en mucho gran parte del mundo no europeo, en particular el Caribe" (392). Así que Benítez Rojo se afilia a un "cuarto paradigma" (ni premoderno, ni moderno, ni postmoderno) que llama "acriollado o mestizo", el cual se ajusta más a la realidad caribeña. Forman parte de este pensamiento Fernando Ortiz, Wilson Harris, Édouard Glissant y escritores como García Márquez, Cabrera Infante y Severo Sarduy, entre otros. Desde ese cuarto paradigma, Benítez Rojo habla de lo específico, en su caso lo caribeño y no lo latinoamericano; pero no lo ve como esencial y estable, a diferencia del "nuestra América" que Mignolo le critica a Retamar. Lo caribeño tampoco es visto como algo homogéneo y así se escapa a la crítica que Cornejo hace del "nuestra América" en singular. Lo que sí hace Benítez Rojo es responder a la exigencia de Cornejo y de Retamar de establecer categorías claves que redefine partiendo de lo mirado mismo, en este caso el Caribe. Por eso, no habla de lenguaje, sino de lenguaje caribeño y 
este se llama ritmo-palabra; no habla del tiempo, sino de tiempo caribeño, y esto es performance; no piensa el mundo desde causa y efecto, sino desde ese movimiento del contrapunteo que es el que acontece en el Caribe. En los siguientes apartes pretendo exponer algunas de las categorías que Benítez Rojo redefine para mapear lo caribeño y luego mostrar cómo intenta apartarse de una noción de lo Caribe homogeneizante o esencialista.

\section{Claves de lectura}

\section{Ritmo-palabra}

A través de la noción de ritmo, que según Benítez Rojo es un Orden que Occidente comenzó a ver como Des-Orden, desafía la idea tradicional de lenguaje como representación de la realidad; desafía la idea del objeto estético como signo que significa, idea que equipara experiencia estética con significación. Para él, "el ritmo es 'la palabra eficaz'. No es ni significante desprovisto de significado ni la palabra que nunca llega a significar lo que desea significar" (204). El ritmo-palabra "es" como la palabra mito, no nombra sino que crea; no denota un referente sino que convoca y hace presente: "Cuando un yoruba baila la danza de Changó, por ejemplo, no solo está bailando el lenguaje de los dioses; está, al mismo tiempo, creando a la deidad misma a través de la danza" (204). Con la palabra-ritmo, un texto como El reino de este mundo de Carpentier no denota la revolución haitiana, sino que a través del mito de Mackandal y sus metamorfosis, la vuelve a hacer presente, viva. El ritmo-palabra en Cien años de Soledad no habla de un mundo con guerras civiles e imposiciones imperialistas; hace presente un Macondo en el que José Arcadio Buendía no aprende que el mundo es redondo sino que lo descubre de nuevo, un Macondo en el que José Arcadio Segundo, más que recordar la aventura de su abuelo que terminó con el descubrimiento del galeón español en medio de la selva, vuelve a vivirla y llega por el río en una balsa de troncos llena de matronas de Francia. En ese mundo, como dice Úrsula, el tiempo da vueltas en redondo y siempre se está volviendo al principio. La palabra-ritmo no es el simulacro del pasado, es el pasado hecho presente.

Esa palabra ritmo que no denota la cosa, sino que la encarna, no la pronuncia un autor, sino que la vive un lector. Es el acto de lectura misma. Es lo leído (Benítez Rojo 204). A partir de ese ritmo-palabra se tejen, no el conocimiento científico ni el filosófico, sino las prácticas narrativas de los llamados por Benítez Rojo "Pueblos del Mar", cuya cultura se transmitió durante muchos años, principalmente a través de la memoria. Esas prácticas narrativas son conocimientos otros que no se legitiman en un referente externo, sino en el hecho de "ser" en el 
momento en el que son emitidas con la voz rítmica del narrador, en el presente del nombrarse (203). Esas prácticas narrativas son esa sabiduría Otra constituida por una red de subcódigos que no denotan un afuera, pero sí se conectan en fuga: "Uno de estos subcódigos nos puede conducir a la Torre de Babel, el otro a la versión arahuaca del Diluvio, otro a los secretos de Eleusis, otro al jardín del unicornio, otros a los libros sagrados de la India y la China y a los cauris adivinatorios de África Occidental" (33). Ese ritmo-palabra, a través de la repetición siempre distinta, es acaso lo que ha hecho posible que "la célula rítmica que trajo el esclavo congo hace cuatro siglos aún no haya desaparecido" (395). En ella se hace vivo otro de los conceptos clave de Benítez: la criollización. Y a este están ligadas otras dos nociones claves: performance y contrapunto.

\section{Performance}

Precisamente porque la palabra-ritmo no denota sino que hace presente, lo caribeño es, según Benítez, performance; es decir, exhibición, actuación, ejecución de un ritual. Esto implica un tiempo no lineal, no sucesivo; no es un tiempo circular, sino más bien pensado como simultaneidad: la plantación big bang que sigue aconteciendo. Performance, actuación, implica también re-presentación; que se haga presente algo. Hay allí una multiplicidad: lo que representa y lo representado. Cada José Arcadio en Cien años de soledad es la re-presentación de otro José Arcadio; pero al volver a hacer presente ese otro, no hay una acumulación de José Arcadios ni una esencia de José Arcadio que permanezca, sino una multiplicidad, una inestabilidad, la del "estremecido colibrí bebiendo de una flor", porque en esa repetición de José Arcadios, como en toda repetición, siempre hay una diferencia, como en cada aleteo (Benítez Rojo 17).

Además, lo representado en el performance es quien lo representa y el acto de representación mismo; lo leído es el lector (el performer) y el acto de lectura misma. Y la multiplicidad es una fuga porque el performance se desplaza a los "espectadores". Benítez Rojo dice: "la performance caribeña, incluso el acto cotidiano de caminar, no se vuelve solo hacia el performer sino que también se dirige hacia un público en busca de una catarsis carnavalesca que se propone canalizar excesos de violencia y que en última instancia ya estaba ahî"' (37-38). Entonces los "espectadores" se vuelven participantes del performance, ellos mismos lectores que al leer son lo leído, y la multiplicidad se sigue dando en fuga. Así, lo caribeño no es, sino que acontece. Por eso es a través del performance como el performer puede "iluminar el misterio de su identidad", porque es en el tiempo del performance y en sus instantes donde se dan los estados de criollización (404). 


\section{Criollización}

Para Benítez Rojo la criollización "no es un proceso - palabra que implica un movimiento hacia delante - sino una serie discontinua de recurrencias, de happenings, cuya única ley es el cambio" (396). Esta inestabilidad se debe a que el Caribe no es una cultura criollizada, sino en estado de criollización. El big bang de la criollización caribeña fue la plantación que arrojó fragmentos culturales en todas las direcciones, fragmentos que a veces se atraen y otras se repelen, en un paso de baile, una línea de un poema, un levantamiento social, etc. Fuerzas como la técnica (radio, televisión, Internet), la política, los acontecimientos históricos o naturales intervienen en esta atracción y rechazo de los fragmentos. Pero no hay proceso ni acumulación, sino estados de criollización.

En este sentido, Benítez Rojo participa de la discusión sobre el mestizaje que es tan importante en el pensamiento latinoamericano. Se inscribe en la línea de Rama y Cornejo Polar, quienes critican el mestizaje pensado como resultado estable y definitivo. Pero, al insistir en la criollización como acontecer, como estados, se aparta del mismo Rama y su noción de transculturación porque esta parece implicar lo transculturado como un resultado alcanzado. Inclusive, se separa un poco de Cornejo Polar, quien aunque critica pensar el mestizaje como "una identidad coherente y uniforme, complaciente y desproblematizada" (Cornejo Polar, "Ensayo" 9), y explica la heterogeneidad como resultado de la condición colonial "que consiste precisamente en negarle al colonizado su identidad como sujeto, en trozar todos los vínculos que le conferían esa identidad y en imponerle otros que lo disturban y desarticulan" (Cornejo Polar, "Ensayo" 9), parece postular lo heterogéneo como en "proceso", no acabado pero sí en proceso, lo que implica una linealidad de la que Benítez Rojo se aparta.

\section{Contrapunto}

A partir del trabajo de Fernando Ortiz en Contrapunteo cubano del tabaco y el azúcar (1940), Benítez Rojo usa el término contrapunto porque permite un "desmantelamiento de las oposiciones binarias", no superándolas sino viéndolas "como opciones de valor estratégico que pueden tomarse como una instancia más del juego infinito de las imposibilidades" (185). El contrapunto permite leer sin centros, dialógicamente, permite ver el pluralismo de las voces y los ritmos en movimiento. El contrapunto "nos refiere a una forma musical según la cual las voces no solo se enfrentan una a la otra, sino que también se superponen una sobre la otra y a la vez se despliegan una tras la otra, paralelamente, interactuando entre sí en una fuga perpetua" (208). Esta forma rítmica que él presenta como una forma de lectura-performance, la forma en que lo 
Caribe mismo funciona, no implica una síntesis de los fragmentos que se encuentran, sino precisamente un espacio de coexistencia "donde el significante jamás es 'uno', ya que lo que escuchamos (leemos) es la superposición siempre incompleta de voces que marchan ad infinitud" (210-211). El contrapunto permite pensar el movimiento, lo caribeño que está en estado de criollización, que es esa "cierta manera" que se repite en la forma de caminar de las viejas antiapocalípticas.

Hay otros conceptos, claves propias, que Benítez Rojo resignifica para nombrar ese mundo otro que es el Caribe: el meta-archipiélago que carece de límites y de centro, que "desborda con creces su propio mar" (18); el caos que "mira hacia todo lo que se repite, reproduce, crece, decae, despliega, fluye, gira, vibra, bulle" (17), pero permite ver que dentro del des-orden hay "estados o regularidades dinámicas que se repiten globalmente" (15); la máquina, esa cadena de máquinas acopladas en la que cada una interrumpe el flujo de la anterior, como lo proponen Deleuze y Guattari, y que se instala en el Caribe para hacer que cuando la modernidad se encuentre con lo africano o lo africano se encuentre con lo taíno se interrumpan los flujos y se dé un acoplamiento que es él mismo parte de otro flujo, un estado de criollización. Estos conceptos-clave o, más bien, las resignificaciones que de ellos, como hemos visto, hace Benítez Rojo surgen del objeto mirado mismo, del Caribe, como lo reclamaba Retamar. Además de buscar categorías propias para mirar lo local, es necesario pensar en cómo se mira eso específico. Esta es otra de las problemáticas de las que se ha ocupado la crítica latinoamericana de las últimas décadas con la que, como en el debate sobre el mestizaje, el pensamiento de Benítez Rojo entra en conversación.

\section{La mirada}

Como hemos dicho, los conceptos-clave: ritmo-palabra, performance, contrapunto, criollización, meta-archipiélago, no son conceptos universales, "surgen" de lo caribeño para mirarlo en su especificidad; responden, en términos de Edward Said, a la mundaneidad de lo mirado. Precisamente porque el Caribe es criollización, hervor, movimiento, se necesitan no solo categorías que permitan hablar de eso, sino una mirada que actualice ese performance; o como dice Cornejo Polar, porque la literatura latinoamericana es heterogénea y múltiple, se necesita una mirada que dé cuenta de ese espesor. La mirada es entonces local, específica, y en ella participan tanto el sujeto que mira como lo mirado.

Además de Cornejo, Retamar y Mignolo, son varios los críticos latinoamericanos que intentan este tipo de miradas descolonizadoras. Beatriz Sarlo, en su libro Borges, un escritor en las orillas, se refiere a una mirada orillera 
que renuncia a los procesos de universalización y ve las tensiones y conflictos entre los discursos que recorren los textos sin pretender estabilizar versiones o significados en ellos. Mabel Moraña, en "Borges y yo. Una primera reflexión sobre el etnógrafo", habla de una mirada desde el pliegue que reconozca el espesor de los textos, que no resuelva si Juan Dahlmann, el personaje de "El sur" de Borges, se muere en el sur por el duelo entre gauchos o en un hospital de la ciudad, víctima de una septicemia. Una lectura desde el pliegue que no resuelva si Mackandal, personaje carpenteriano, se muere en la hoguera o sale volando mosquito zumbón y permanece en el reino de este mundo como ciempiés, tarántula, cocuyo de luces verdes.

Benítez Rojo propone, como Sarlo y Moraña, una forma de lectura para poder ver eso otro, que en su caso no es lo latinoamericano, sino lo caribeño. Se refiere a esta como una "segunda lectura" que deje de ser un espejo del lector y revele la textualidad propia del Caribe (15). Es una lectura que se detiene en los ritmos propios y percibe la multiplicidad de las fuentes (42); da cuenta de las regularidades que "se desgajan del interplay de los ritmos" (43), pero va más allá de la dialéctica que haría que esos ritmos se resuelvan en el mestizaje y pone en evidencia que el mestizaje no es una síntesis porque "nada que sea ostensiblemente sincrético constituye un punto estable" (42). Más bien, esta "segunda lectura" hace de las oposiciones un flujo, una fuga, un contrapunto.

Un ejemplo de esta forma de leer que propone y lleva a cabo Benítez Rojo lo presenta Santiago Villa en el estudio comparativo que hace de la obra del historiador colombiano Germán Arciniegas y la de Benítez Rojo. Villa muestra cómo la lectura que Benítez Rojo hace de la piratería es "una segunda lectura" en la que "el foco de atención no estaría en los forcejeos políticos de Europa en el Caribe, sino en el contexto cultural que crea la piratería. Hawkins no es exclusivamente el pirata de la reina, sino un eje, una pieza en la "máquina del Caribe" (194). Según Villa es una lectura que "descentra el referente europeo, y asume el riesgo de colocar todo fenómeno social en un contexto de flujos culturales, de Caos, para construir una visión multiforme del Caribe" (195).

Esta "segunda lectura" propone leer Contrapunteo cubano... de Fernando Ortiz "como un texto dialógico y acéntrico en cuyo pluralismo de voces y de ritmos no solo se dejan escuchar las más variadas disciplinas y las ideologías más irreconciliables, sino también enunciados que corresponden a dos formas de conocimiento, de saber" (Benítez Rojo 189) y así también leer el Caribe y el texto de Benítez Rojo mismo. Esta "segunda lectura" es dialógica y acéntrica y permite oír la pluralidad de voces y ritmos. No tiene como finalidad hallar resultados, "sino procesos, dinámicas y ritmos que se manifiestan dentro de lo marginal, 
lo residual, lo incoherente, lo heterogéneo o, si se quiere, lo impredecible que coexiste con nosotros en el mundo de cada día" (17).

Esa lectura permite ver esa "cierta manera" de lo caribeño, permite ver "una isla que se repite", aunque cada una de esas repeticiones "entraña necesariamente una diferencia y un paso hacia la nada" (17). Ver "de cierta manera" para reconocer al otro es un esfuerzo descolonizador que pluraliza y ayuda al reconocimiento del otro. Reconocer al otro es ayudarle a su resistencia y participar de su existencia.

Cuando Benítez Rojo escribe sobre el Caribe no solo está mirando de "cierta manera", sino escribiendo así. De ahí que al tema de la mirada se le sume otro. ¿Cómo nombrar lo mirado? ¿Cómo dar cuenta de eso múltiple e inestable, de esa isla que se repite? Benítez Rojo teje imágenes, enumeraciones, en una prosa que no pretende estabilizar, una prosa que desborda:

Este curioso accidente geográfico le confiere a toda el área, incluso a sus focos continentales, un carácter de archipiélago, es decir, un conjunto discontinuo (¿de qué?): condensaciones inestables, turbulencias, remolinos, racimos de burbujas, algas deshilachadas, galeones hundidos, ruidos de rompientes, peces voladores, granizos de gaviotas, aguaceros, fosforescencias nocturnas, mareas y resacas, inciertos viajes de la significación; en resumen, un campo de observación muy a tono con los objetivos de Caos. (16)

Así responde a otro de los desafíos que tienen la crítica y la teoría latinoamericanas, que señala entre otros Mignolo: cómo dar cuenta de lo específico sin pretender revelarlo, sin estabilizarlo, sin esencializarlo. ¿Cómo ver y hablar de ese estremecido colibrí bebiendo de una flor? Benítez Rojo lo intenta resignificando categorías, tratando de reconocer multiplicidad de fuentes y voces, no plegándose a los sincretismos, estableciendo relaciones y no resultados, performando en su escritura esa "cierta manera" de caminar de las viejas antiapocalípticas, nombrando esa "cierta manera" con su ritmo-palabra, para al nombrarla reconocerla, re-presentarla, hacerla presente, iluminando el escenario de su performance para que sea visto, oído, vivido.

\section{El caminar de las viejas antiapocalípticas}

[...] una hermosísima tarde de octubre, hace años, cuando parecía inminente la atomización del meta-archipiélago bajo los desolados paraguas de la catástrofe nuclear. Los niños de La Habana, al menos los de mi barrio, habían sido evacuados, y un grave silencio cayó sobre las calles y el mar. Mientras la burocracia estatal buscaba noticias de onda corta y el ejército se atrincheraba inflamado por los discursos patrióticos y los comunicados 
oficiales, dos negras viejas pasaron de "cierta manera" bajo mi balcón. Me es imposible describir esta "cierta manera". Solo diré que había un polvillo dorado y antiguo entre sus piernas nudosas, un olor de albahaca y hierbabuena en sus vestidos, una sabiduría simbólica ritual, en sus gestos y en su chachareo. Entonces supe de golpe que no ocurriría el Apocalipsis. Esto es: las espadas y los arcángeles y las trompetas y las bestias y las estrellas caídas y la ruptura del último sello no iban a ocurrir. Nada de eso iba a ocurrir por la sencilla razón de que el Caribe no es un mundo apocalíptico. (Benítez Rojo 25)

Benítez Rojo sabe que el "Caribe", "lo caribeño" son términos que "deben ser vistos como inestables construcciones de plasma, en perpetua fluidez y cambio" (389); y lo problematiza al poner entre comillas ese "cierta manera" de lo caribeño. Reconoce la multiplicidad de lenguajes, razas y tiempos en el Caribe; habla de la imposibilidad de definirlo geográficamente, parte de su fragmentación e inestabilidad, y sin embargo, no renuncia a lo "caribeño". Aboga por la posibilidad de existir sin ser esencia.

Postula lo caribeño como esa "cierta manera" de caminar de las viejas antiapocalípticas, como el estremecimiento del colibrí, su inquietud permanente, su aletear constante no para cruzar a alguna parte sino para permanecer bebiendo de una flor: posibilidad de ser en movimiento.

En la coexistencia de ritmos descentrados, cuando el performer hace presente a través del ritmo-palabra y se da un estado de criollización, está lo caribeño. No necesariamente en el espesor del que Cornejo habla con respecto a la heterogeneidad latinoamericana, sino en el contrapunto, en el movimiento, en la actuación, en la re-presentación. Esa cierta manera es móvil, pero no por eso totalmente inestable, pues en el ritmo que ella se da, se repite y aunque cada repetición es otra, siempre permanece algo de lo que se desplaza. Esa palabraritmo no revela la esencia caribeña, la performa y actualiza. El lenguaje no denota lo caribeño, lo performa.

\section{Una fuga del Aleph}

Benítez Rojo pretende proponer esa resistencia del "cierta manera" como una "estética de no violencia" porque no permite centros ni estabilidades (37); sin embargo, es necesario reconocer las tensiones y luchas de poder que acontecen en los discursos y no asumir un tono celebratorio. Uno de los juegos de poder que ha señalado la crítica con respecto a Benítez Rojo tiene que ver con su inscripción en la ley patriarcal al reproducir lo caribeño como femeni- 
no y erótico, como lo anota Frances Aparicio en su artículo "Performing the Caribbean in American Studies". Pero Benítez, en ese esfuerzo por abarcarlo todo, había ya reconocido que no hay que caer en idealizaciones y que no hay ninguna máquina exenta de represión (45). Además había señalado: "Cierto que no es una máquina tecnológica-positivista indiferente a la conservación de ciertos vínculos sociales, pero en su ahistoricidad perpetúa mitos y fábulas que pretenden legitimar la ley patriarcal y ocultan la violencia inherente a todo origen sociológico" (45). Benítez Rojo no lo oculta, sabe que participa de esa ley patriarcal y lo dice.

Y eso es parte de la mundaneidad de su texto y de su propia lógica patriarcal, todo lo nombra, todo lo contiene, hasta las críticas. Como Cien años de soledad y las narrativas totalizadoras del boom, La isla que se repite es otro Aleph. Michael Palencia Roth, en su artículo "Los pergaminos de Aureliano Babilonia", criticaba a Borges porque solo describía el Aleph, mientras García Márquez lo creaba (409). A mí me da un respiro el que Borges nos deje espacio. Benítez Rojo no enuncia el Aleph como Borges, lo crea como García Márquez o más bien lo re-crea en su performance. Ese Aleph-Caribe parece devorarnos, pero no todo es Macondo, aunque Macondo se haga presente en cualquier parte o momento en el que se lea el texto. Tampoco el Aleph de Benítez Rojo lo es todo; es el Caribe. Lo local y lo específico no se pierde. Caribe es esa "cierta manera" de caminar de las viejas antiapocalípticas. Para seguir en el contrapunto con el Caribe, que no soy, hay que insistir en la mirada orillera que me permite reconocerlo y distanciarme de él.

\section{Obras citadas}

Aparicio, Frances. "Performing the Caribbean in American

Studies". American Quarterly 50.3 (1998): 636-644.

Benítez Rojo, Antonio. La isla que se repite. Barcelona: Casiopea, 1998.

Cornejo Polar, Antonio. "Ensayo sobre el sujeto y la representación en la literatura latinoamericana: algunas hipótesis". Hispamérica.

Revista de Literatura Hispanoamericana 22.66 (1993): 3-15.

—. "Para una teoría literaria hispanoamericana: a veinte años de un debate decisorio".

Mapas culturales para América Latina. Culturas híbridas-no simultaneidad-

modernidad periférica. Comp. Sarah de Mojica. Bogotá: CEJA; Pensar, 2001. 247-249.

Fernández Retamar, Roberto. Para una teoría de la literatura

hispanoamericana. Bogotá: Instituto Caro y Cuervo, 1995.

Mignolo, Walter. "Teorizar a través de fronteras culturales". Revista

de Crítica Literaria Latinoamericana 33 (1991): 103-112. 
Moraña, Mabel. "Borges y yo. Primera reflexión sobre "El Etnógrafo"”.

Crítica impura. Madrid: Iberoamericana Vervuert, 2004. 103-122.

Palencia Roth, Michael. "Los pergaminos de Aureliano Babilonia".

Revista Iberoamericana 49.123-124 (1983): 403-417.

Sarlo, Beatriz. Borges, un escritor en las orillas. Madrid: Siglo XXI, 2007.

Villa, Santiago. "En torno al Caribe: Arciniegas y Benítez

Rojo". Historia Crítica 29 (2005): 185-195. 